1999; 97: 425-7, 431.

4 Lehmann A, Zeitler C, Lang J, Isgro F, Kiessling AH, Boldt J. A comparison of the Arndt endobronchial blocker with a double lumen tube in robotic cardiac surgery (German). Anasthesiol Intensivmed Notfallmed Schmerzther 2004; 39: 353-9.

5 Walther T, Falk V, Metz S, et al. Pain and quality of life after minimally invasive versus conventional cardiac surgery. Ann Thorac Surg 1999; 67: 1643-7.

\section{Ondansetron and carpopedal spasm}

To the Editor:

Ondansetron, a serotonin $\left(5-\mathrm{HT}_{3}\right)$ antagonist, is claimed to lack direct blocking action on the dopaminergic system; therefore, it was considered to be free of extrapyramidal symptoms (EPS). However, ondansetron-associated EPS have been reported on several occasions. ${ }^{1,2}$ We describe an unusual presentation of ondansetron-induced EPS characterized by carpopedal spasm.

A 44-yr-old woman with a history of acoustic neuroma underwent removal of a craniotomy plate. The anesthetic induction (propofol, midazolam, succinylcholine, fentanyl) and the course of her anesthesia (isoflurane, hydromorphone) were uneventful. As prophylaxis for nausea she received ondansetron $8 \mathrm{mg}$ in in divided doses, at the beginning and end of surgery. During emergence she was hyperventilating. Following extubation her hands were in a flexed and fisted position and her legs were in plantar flexion (carpopedal spasm) (Figure). She was noted to be sweating profusely and a dyskinetic tremor of her entire body was observed. In light of the patient's hyperventilation this was interpreted as hypocalcemia, and calcium chloride $200 \mathrm{mg} i v$ was given without effect. Shortly thereafter, her eyes were noted to be rolling up (oculogyric crises). At that point a dystonic reaction to ondansetron was suspected and $25 \mathrm{mg}$ of diphenhydramine was given without effect. The patient was responsive, cooperative, and following commands. In the recovery room her room air oxyhemoglobin saturation was > 95\% and body temperature was $36.6^{\circ} \mathrm{C}$. Postoperatively, carpopedal spasm dominated the clinical presentation. She was awake, alert and oriented. On examination she was unable to relax her hands and feet; however, she had intact strength in all four extremities, and Babinski signs were absent. Deep tendon reflexes were intact and symmetric. Her sensory exam was intact to light touch, vibratory, and pinprick sensation and her tongue was in the midline. Finger-to-nose and heelto-shin examinations were bilaterally intact. Serum
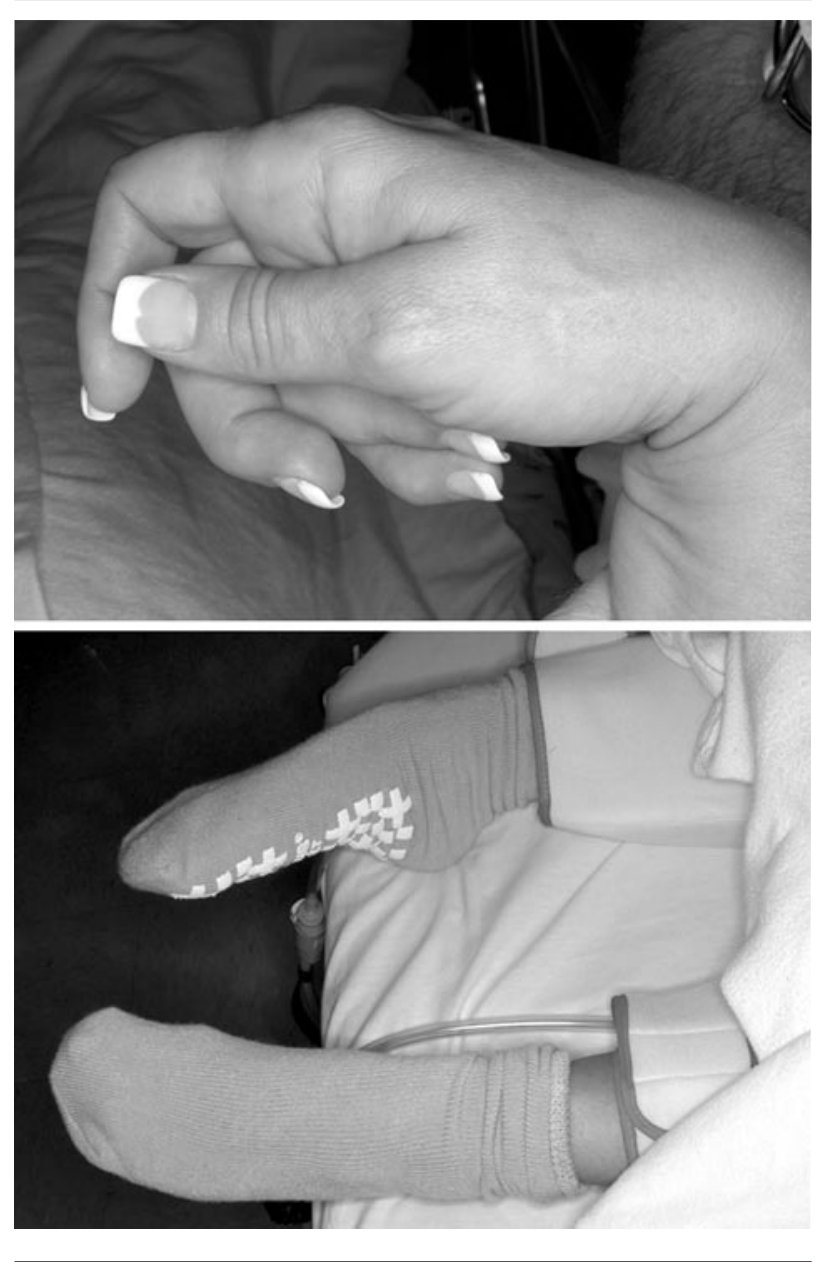

FIGURE Carpopedal spasm induced by ondansetron.

electrolytes were within normal limits. Because the patient had pronounced twitching of the corner of the mouth (right hemi-facial spasm/oromandibular dystonia), a blink reflex testing by electromyography was ordered to rule out facial nerve abnormalities. Both facial and trigeminal nerve conduction studies were normal. A magnetic resonance imaging scan obtained before surgery was normal, and was not repeated postoperatively. Dystonic posture of both wrists and fingers resolved by the following morning at which point she was discharged.

We describe a rare EPS reaction to ondansetron with the clinical picture dominated by protracted carpopedal spasm. Despite the fact that ondansetron has no clear-cut ability to block dopamine receptors (an effect necessary to induce EPS), ${ }^{3}$ anti-dopaminergic adverse effects (EPS) have been described, especially 
when ondansetron is given in larger doses in the chemotherapy setting. ${ }^{4}$

We first suspected that the pathogenesis of carpopedal spasm was related to hyperventilation-induced hypocalcemia. However, the patient stopped hyperventilation on request, carpopedal spasm did not improve with intravenous calcium, and the subsequent serum ionized calcium concentration was normal. Presence of oromandibular dystonia, oculogyric crisis, and diffuse sweating strongly suggested EPS to ondansetron, a reaction we have witnessed on several occasions in the past. ${ }^{1,2}$ However, our patient followed commands and responded to all questions immediately upon emerging from anesthesia which was in contrast to our previous experience. ${ }^{1,2}$ While there are some similarities between previously reported cases, the present case is unique in that the long lasting carpopedal spasm dominated with presentation. At the same time, the common characteristics with our previously reported cases $^{1,2}$ included the observations that EPS delayed the patient's discharge, incurred significant cost for an extensive neurological evaluation, and all symptoms and signs of EPS resolved without consequence within the first day. Unfamiliarity with the benign outcome of these events may be very frightening for both the family members and anesthesiologist.

\section{Harish Ramakrishna MD*}

Terrence L. Trentman MD*

Brian A. Hall MD $\dagger$

Juraj Sprung MD PhD $\dagger$

Mayo Clinic College of Medicine, Scottsdale,

Arizona* and Rochester, $†$ USA

E-mail: sprung.juraj@mayo.edu

Accepted for publication October 1, 2007.

\section{References}

1 Ritter MJ, Goodman BP, Sprung J, Wijdicks EF.

Ondansetron-induced multifocal encephalopathy. Mayo Clin Proc 2003; 78: 1150-2.

2 Sprung J, Choudhry FM, Hall BA. Extrapyramidal reactions to ondansetron: cross-reactivity between ondansetron and prochlorperazine? Anesth Analg 2003; 96: 1374-6.

3 Hedenmalm K, Guzey C, Dabl ML, Yue QY, Spigset $O$. Risk factors for extrapyramidal symptoms during treatment with selective serotonin reuptake inhibitors, including cytochrome P-450 enzyme, and serotonin and dopamine transporter and receptor polymorphisms. J Clin Psychopharmacol 2006; 26: 192-7.

4 Dobrow RB, Coppock MA, Hosenpud JR. Extrapyramidal reaction caused by ondansetron. J Clin Oncol 1991; 9: 1921.

\section{A maneuver to facilitate endotracheal intubation using the GlideScope ${ }^{\circledR}$}

\section{To the Editor:}

The GlideScope ${ }^{\circledR}$ (Verathon, Bothell, WA, USA) is a video laryngoscope with a high resolution camera embedded within the blade which gives an improved view of the glottis, and may be useful for difficult intubations. ${ }^{1-3}$ Our experience with the GlideScope ${ }^{\circledR}$ includes 120 patients to date. In 25 cases, there was some difficulty in directing the endotracheal tube (ETT) into the larynx despite a good view of the larynx on the video screen.

Small mouths, a narrow oral cavity and/or a large tongue make it difficult to manipulate the ETT into the oral cavity. Blind introduction of an ETT before its visualization on the video screen can injure the oral cavity, and several cases of palatopharyngeal injury have been reported. ${ }^{4,5}$ To reduce these complications, several maneuvers have been suggested, including introduction of the ETT into the mouth prior to the insertion of the GlideScope ${ }^{\circledR},{ }^{4}$ or insertion of the ETT parallel and as proximal as possible to the laryngoscope blade, attempting to reproduce its course. ${ }^{5}$

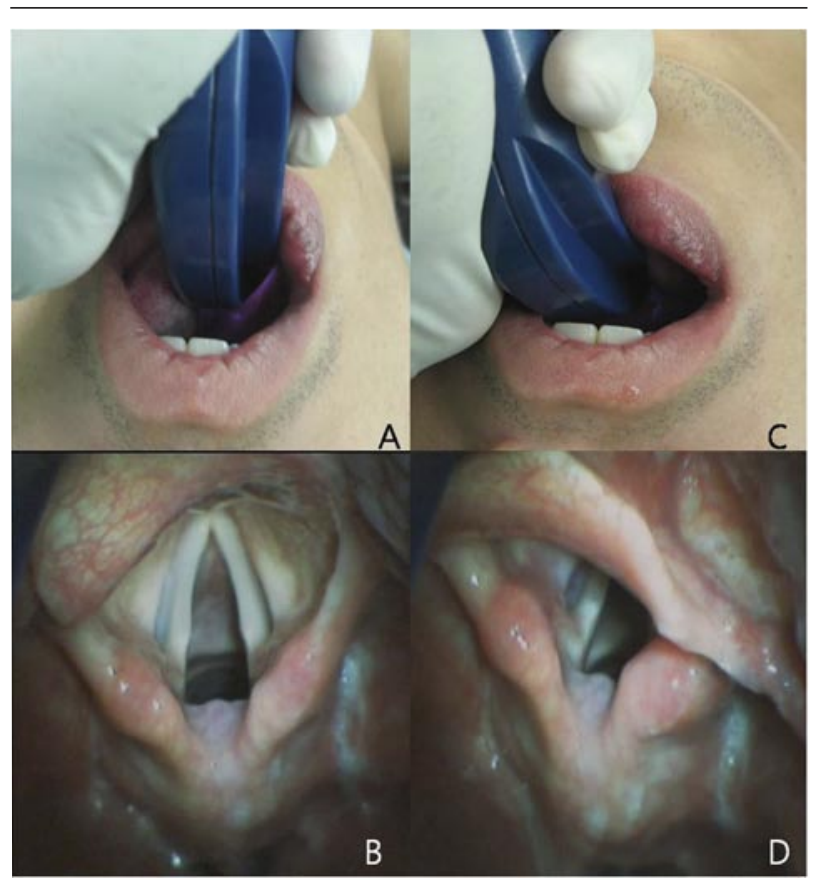

FIGURE Laryngoscopy and view of the larynx as seen on the GlideScope ${ }^{\circledR}$ video screen. A) Introduction of the blade of the GlideScope ${ }^{\circledR}$ along the midline of the tongue. B) View of the larynx when approached at the midline. C) Introduction of the blade of the GlideScope ${ }^{\circledR}$ nearer to the left corner of the mouth. D) View of the larynx when approached nearer to the left corner of the mouth. 